\title{
The effect of phenol and PAH contaminants on different species of arbuscular mycorrhizal fungi
}

\author{
Monika MALICKA ${ }^{1}$ - Franco MAGURNO² - Katalin POSTA ${ }^{3}-$ \\ Zofia PIOTROWSKA-SEGET ${ }^{4}$ \\ 1: Department of Microbiology, Faculty of Biology and Environmental Protection, University of Silesia, \\ Jagiellońska 28 Street, 40-032, Katowice, Poland; monika.malicka@us.edu.pl \\ 2: Department of Botany and Environmental Protection, Faculty of Biology and Environmental Protection, \\ University of Silesia, Jagiellońska 28 Street, 40-032, Katowice, Poland; franco.magurno@gmail.com \\ 3: Institute of Genetics, Microbiology and Biotechnology, Szent István University, Páter Károly Street 1, Gödöllő \\ H-2100, Hungary; posta.katalin@mkk.szie.hu \\ 4: Department of Microbiology, Faculty of Biology and Environmental Protection, University of Silesia, \\ Jagiellońska 28 Street, 40-032 Katowice, Poland; zofia.piotrowska-seget@us.edu.pl
}

Keywords: arbuscular mycorrhizal fungi, phenol, polynuclear aromatic hydrocarbons

\section{Introduction}

Arbuscular mycorrhizal fungi (AMF) are ubiquitous plant symbionts which colonize roots of about $80 \%$ of known terrestrial plant species (Smith and Read, 2008). AMF improve plant growth by provision with nutrients, induce primal plant systemic resistance and protect plants from abiotic stress factors like drought, salinity, heavy metals and hydrocarbons (Bothe et al., 2010; Rajtor and Piotrowska-Seget, 2016; Nguyen et al., 2017; Nguyen et al., 2018). The objects of this study was to assess the level of oxidative stress and development of different AMF species and their effect on a plant growth in the presence of phenol and PAHs.

\section{Materials and methods}

Three AMF species, Funneliformis caledonium, Diversispora varaderana and Claroideoglomus walkerii, isolated from the site age-contaminated with phenol and PAHs, were used to inoculate Lolium perenne germinated in a substrate contaminated with different concentrations of phenol and PAHs. Plants were inoculated with single-species AMF inoculants and a mixture of three AMF species. Negative controls were non-AMF plants grown in non-contaminated (NC) substrate. After 6 months roots, shoots and AMF spores were harvested to assess the plant growth and biomass, mycorrhizal colonization, number of AMF spores and the level of oxidative stress (lipid peroxidation, DNA damage) and antioxidant activity (catalase, peroxidase, superoxide dismutase) in plant tissues and AMF spores.

\section{Results and discussion}

All studied AMF species had positive effects on plant growth and biomass, especially under low (LC) and medium (MC) phenol+PAHs contamination, but shaped differently plant morphology. Better effects were obtained with single-species AMF than with mixed AMF inoculum. F. caledonium and $D$. varaderana increased the length and biomass of roots and shoots, with low effect on the number of leaves per plant. Plants inoculated with C. walkerii had shorter shoots and very low root biomass, but higher number of leaves. In non-AMF plants the level of oxidative stress and antioxidant activity was increased with the growing concentration of contaminants. All tested AMF species decreased the oxidative 
damage in plants but had different effects on the activity of antioxidative enzymes. $F$. caledonium increased the antioxidative activity in LC and NC pots and decreased it in MC and high contaminated (HC) pots, compared to non-AMF control. D. varaderana and C. walkerii increased the antioxidative activity in all of the treatments, except HC. Root mycorrhizal colonization was the highest in LC and MC pots and the lowest in HC pots. The number of $F$. caledonium spores was not affected by the contamination, while the number of $D$. varedarana and $C$. walkerii spores was decreased in the contaminated pots. Oxidative stress in AMF spores was increased in MC and $\mathrm{HC}$ treatments. The presence of contaminants increased the antioxidative activity in $F$. caledonium spores with the opposite effects on $D$. varaderana spores. Antioxidative activity in $C$. walkerii spores was not affected by the contamination.

\section{Conclusions}

Summing up, all studied AMF species showed resistance to the presence of contaminants with positive effects on plant growth showing different antioxidative response. LC (5/20 mg*kg-1 phenol/PAHs) and MC (15/60 mg*kg-1 phenol/PAHs) stimulated the development of mycorrhiza, which suggests that both symbionts take the highest benefits from symbiotic association under moderate stress. Toxic effects on mycorrhiza development were demonstrated under HC (30/120 mg*kg-1 phenol/PAHs). Surprisingly, inoculation with the mixture of AMF species had positive effects on plants in the presence of contaminants, but decreased the plant growth in NC pots, which might be associated with the invasive development of $C$. walkerii.

\section{Acknowledgement}

This research was supported by the project PRELUDIUM 13 No. 2017/25/N/NZ8/01676 founded by The National Science Centre (Poland).

\section{References}

Bothe H., Regvar M., Turnau K. (2010): Arbuscular mycorrhiza, heavy metal, and salt tolerance. In: Soil Heavy Metals. Soil Biology, vol 19. Springer, Berlin, Heidelberg

Nguyen H.D., Csintalan Z., Posta K. (2018): Arbuscular mycorrhizal fungi mitigate negative effects of combined drought and heat stress on tomato plants. Plant Physiology and Biochemistry 132. 297-307. DOI: https://doi. org/10.1016/j.plaphy.2018.09.011

Nguyen H.D., Mayer Z., Pék Z., Helves L., Posta K. (2017): Combined inoculation of arbuscular mycorrhizal fungi, Pseudomonas fluorescens and Trichoderma spp. for enhancing defense enzymes and yield of three pepper cultivars. Applied Ecology and Environmental Research 15:3. 1815-1829. DOI: 10.15666/ aeer/1503_18151829

Rajtor M., Piotrowska-Seget Z. (2016): Prospects for arbuscular mycorrhizal fungi (AMF) to assist in phytoremediation of soil hydrocarbon contaminants. Chemosphere 162. 105-16. DOI: https://doi. org/10.1016/j.chemosphere.2016.07.071

Smith S., Read D. (2008): Mycorrhizal Symbiosis. Academic Press, Cambridge, Massachusetts. 